\title{
A Very Unusual Cause of Persistent Cough Diagnosed by Bronchoscopy
}

\author{
Yamilex Urbano-Aranda ${ }^{a}$ María J. Espinosa de los Monteros ${ }^{a}$ \\ Ángel Sánchez-Castaño ${ }^{\mathrm{b}}$ Raquel Labra-González ${ }^{\mathrm{b}}$ \\ Departments of a Pulmonary Medicine and ${ }^{\mathrm{b}}$ Internal Medicine, Virgen de la Salud Hospital, Toledo, Spain
}

\section{Case Report}

A 68-year-old nonsmoking male presented in 2007 with a history of hiatal hernia, long-standing bronchial asthma requiring high-dose oral corticosteroids on a chronic basis, and visceral leishmaniasis (VL) with shock secondary to acute adrenal gland insufficiency. He reported worsening dyspnea and a persistent cough for several months. The patient showed good treatment compliance and an adequate control of factors that could favor the persistence of the asthma symptoms (such as hiatal hernia).

Physical examination revealed only a greatly diminished vesicular murmur upon pulmonary auscultation. The leukocyte count was 7,600 cells $/ \mathrm{mm}^{3}$ (65\% neutrophils, $26 \%$ lymphocytes and $7.7 \%$ monocytes). The thyroid function study and biochemistry parameters proved normal, except creatinine $(1.40 \mathrm{mg} / \mathrm{dl})$ and triglycerides (220 mg/dl).

In accordance with the protocol for difficult-to-control asthma, a pulmonary function study was made: forced vital capacity (FVC) 2,630 $\mathrm{ml}$ (65\%), forced expiratory volume in the first second $\left(\mathrm{FEV}_{1}\right) 2,040 \mathrm{ml}(70 \%)$, $\mathrm{FEV}_{1} / \mathrm{FVC} 74 \%$, and a positive response to bronchodila- tors. The prick test for common pneumoallergens proved negative. Chest X-rays and computed tomography (CT) showed no significant alterations, except right basal segmental atelectasis and adenopathies of a reactive appearance (fig. 1). Considering the persistent cough despite optimum treatment, bronchoscopy was decided upon, the findings being suggestive of inflammatory thickening of the dividing carinal region of the segmental bronchi of the right upper lobe (RUL; fig. 2). A histological study of the bronchial biopsy revealed intense acute and chronic inflammation, squamous metaplasia, and the presence within the macrophages of oval structures containing a large nucleus and a prominent kinetoplast (fig. 3).

What is your diagnosis?

\section{KARGER \\ Fax +4161306 1234}

E-Mail karger@karger.ch

www.karger.com
(C) 2012 S. Karger AG, Basel

0025-7931/12/0843-0246\$38.00/0

Accessible online at: www.karger.com/res
Yamilex Urbano-Aranda, MD

Department of Pulmonary Medicine Virgen de la Salud Hospital

30 Barber Av., ES-45004 Toledo (Spain)

Tel. +34 925237 310, E-Mail yurbano@ sescam.jccm.es 
Fig. 1. Chest CT (baseline slice) showing a right basal segmental atelectasis.

Fig. 2. Endoscopic view of the entry to the bronchus of the RUL, showing inflammatory thickening of the dividing carinal region of the segmental bronchi.

Fig. 3. Histological view of the biopsy specimen, showing intense acute and chronic inflammation, and the presence within the macrophages of oval structures (arrows) containing a large nucleus and prominent kinetoplast. HE. $\times 1,000$.
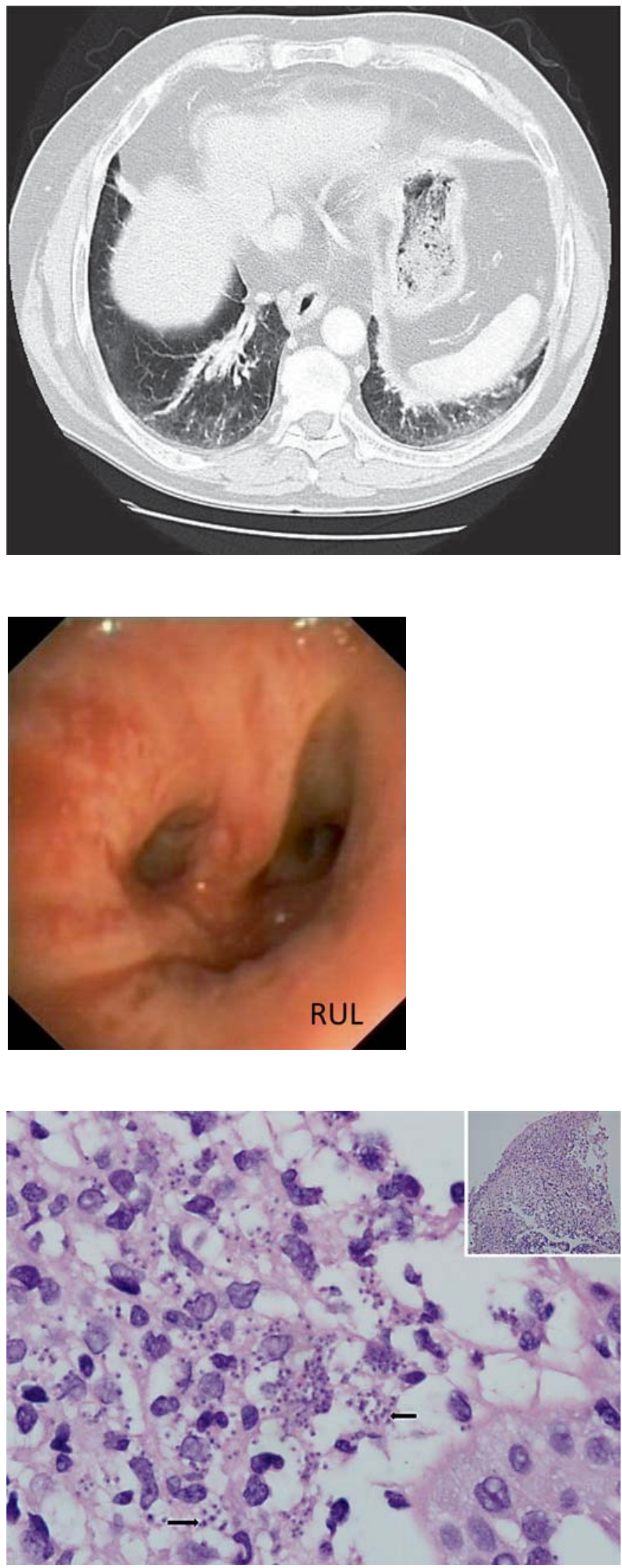

Respiration 2012;84:246-249 
Leishmaniasis is an infectious disease caused by protozoa belonging to the genus Leishmania, such as L. donovani, L. tropica, L. major and L. infantum, with a biological cycle comprising an extracellular form or promastigote and an intracellular form or amastigote that mainly attacks cells of the reticuloendothelial system. The disease is transmitted to humans through the bite of the female sand fly (Phlebotomus). Wild and domestic animals such as foxes, jackals, rodents, wolves and dogs act as reservoirs, humans in turn being the only accidental hosts. Three clinical forms of leishmaniasis are described: VL also called kala azar, cutaneous, and mucocutaneous leishmaniasis. Many of these forms, which can affect several organs (lungs, larynx, gastrointestinal tract, etc.), are considered opportunistic infections.

The isolation of Leishmania amastigotes in lung tissue and tracheobronchial mucosa in humans is very rare, and has been described mainly in immunosuppressed patients and individuals with acquired immunodeficiency syndrome. The occurrence of these different forms of leishmaniasis depends on both the type of parasite and the host immune response. The disease is endemic in some regions of Asia, Africa, South and Central America, and in the Spanish Mediterranean region [1].

The lung lesion most often seen in patients with VL is chronic diffuse interstitial pneumonitis, with the involvement of several immune system cells [2]. However, other much less common forms of tracheobronchial involvement due to Leishmania have been reported, such as 'tree in bud' pattern, cavitated infiltrates, lung nodules, tracheal stenosis, and hilar and mediastinal adenopathies [3-8].

In our patient, diagnostic bronchoscopy was decided upon to rule out possible endobronchial or tracheal lesions (not evidenced by the thoracic CAT scan) capable of accounting for the persistent cough, since the patient continued to have an uncontrolled cough despite the high oral corticosteroid doses administered for the treatment of asthma (deflazacort $6 \mathrm{mg}$ every $12 \mathrm{~h}$ ), although he required continuous dose increases due to the presentation of very frequent exacerbations. It should be pointed out that the flexible bronchoscopy performed revealed no alterations in the bronchial mucosa or right basal segments to justify the taking of a biopsy at that level and the atelectasis described in the chest CT; we, therefore, assumed that it could be due to a mucus plug.

Although Piens et al. [9] and Kotsifas et al. [10] have shown that there are very few reports of tracheobronchi-

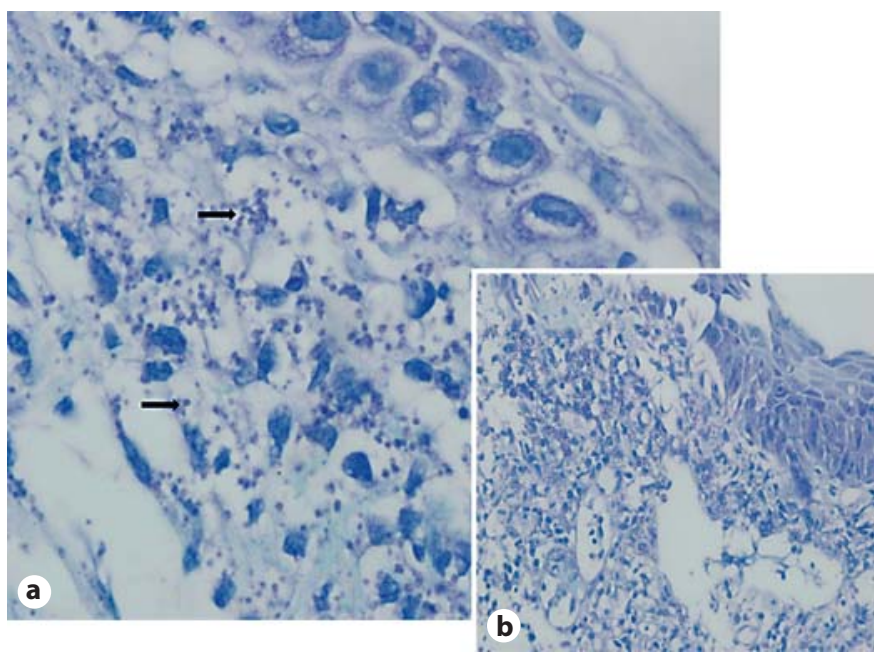

Fig. 4. a Giemsa stain showing structures within the macrophages suggestive of Leishmania amastigotes. $\times 1,000$. b Giemsa stain $\times 400$.

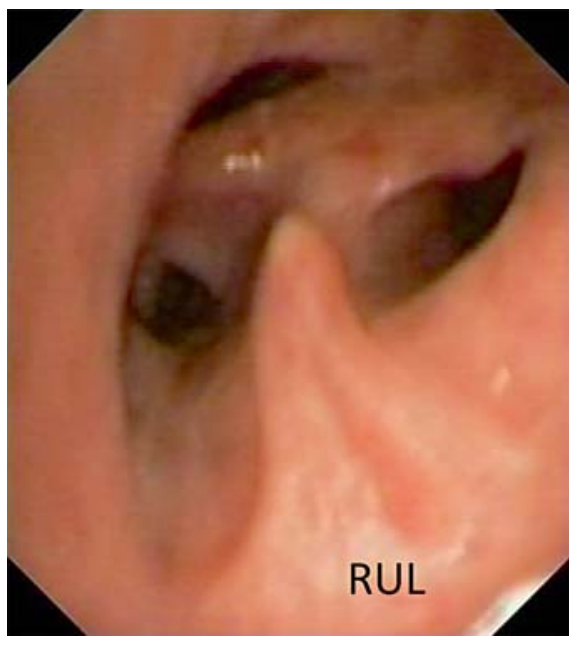

Fig. 5. Endoscopic view of the segmental bronchi of the RUL after treatment with amphotericin B. Note the complete disappearance of signs of inflammation.

al mucosal lesions due to Leishmania, we consider it interesting to note that, despite the immune suppression found in our patient, only the bronchial mucosa was seen to be affected with no other organ involvement (negative bone marrow study). This underscores the relevant and exceptional nature of our case.

Direct observation of the protozoa in bone marrow aspirate is known to be one of the best diagnostic options 
in VL. However, molecular biology techniques are now a significant alternative for demonstrating the presence of Leishmania and in our patient the diagnosis was confirmed by polymerase chain reaction, in addition to the visualization of structures suggestive of Leishmania in the bronchial biopsies (fig. $4 \mathrm{a}, \mathrm{b}$ ).

The patient was treated with liposomal amphotericin B, $400 \mathrm{mg} /$ day for 5 days and subsequently $400 \mathrm{mg} /$ week for 4 weeks (total dose 3,600 mg), with good clinical response as evidenced over 8 months of follow-up, controlling the symptoms without the need for oral corticosteroids (table 1). At this point, a control bronchoscopy showed a complete disappearance of the signs of inflammation in the RUL (fig. 5), and the histological study of the bronchial biopsies revealed no significant alterations.

We feel that in this case it is very difficult to know whether the patient's leishmaniasis was due to reinfection or reactivation as he presented fever, nodular splenomegaly and pancytopenia in 2007. He received a total of 2,700 $\mathrm{mg}$ of amphotericin in split doses, and all clinical, analytical and radiological manifestations suggesting LV disappeared. The patient lives in an area with a high incidence of this illness; although leishmaniasis has not been a mandatory notifiable disease in Spain since 1996, and its incidence then was 0.2 cases per 100,000 inhabitants, a study published in 2008 based on cases requiring hospital admission between 1999 and 2003 indicated an incidence of $0.64-1.1$ cases per 100,000 inhabitants [11] in this area. Despite the absence of objective findings that can assure us that he had pulmonary involvement in 2007 , it is, however, possible to confirm better control of his asthma following treatment with amphotericin $\mathrm{B}$, hence we believe that there probably was already pulmonary involvement.
Table 1. Difference between respiratory functional values and quality of life before and after treatment with amphotericin

\begin{tabular}{lrrr}
\hline & $\begin{array}{l}\text { Before } \\
\text { treatment }\end{array}$ & $\begin{array}{l}\text { After } \\
\text { treatment }^{\mathrm{a}}\end{array}$ & Difference \\
\hline $\mathrm{FVC}, \mathrm{ml}$ & 2,630 & 2,770 & 140 \\
$\mathrm{FVC}, \%$ & 65 & 68 & 3 \\
$\mathrm{FEV}_{1}, \mathrm{ml}$ & 2,040 & 2,140 & 100 \\
$\mathrm{FEV}_{1}, \%$ & 70 & 74 & 4 \\
$\mathrm{FEV}_{1} / \mathrm{FVC}, \%$ & 74 & 7 & 3 \\
Response to BD $_{\text {ACT (score) }}$ & + & + & \\
& 13 & 23 & 10 \\
\hline
\end{tabular}

$\mathrm{FEV}_{1} / \mathrm{FVC}=$ Ratio between $\mathrm{FEV}_{1}$ and $\mathrm{FVC} ; \mathrm{BD}=$ bronchodilators; $\mathrm{ACT}=$ Asthma Control Test.

a Seven months after administration of liposomal amphotericin B.

It can be concluded that when patients with continuing respiratory symptoms not explained by the underlying disease fail to respond to appropriate treatment and present conditions leading to immunosuppression, particularly in the presence of a history of VL, the differential diagnosis must include probable endobronchial Leishmania disease, particularly if the thoracic CT study offers no likely alternative diagnosis. Furthermore, in these cases bronchoscopy is essential for establishing a diagnosis.

\section{Key Words}

Bronchial asthma - Chronic cough • Corticosteroids •

Diagnostic bronchoscopy $\cdot$ Leishmaniasis

\section{References}

1 Martínez R, Esteban JG, Ribas A, Doganci L: Protozoa in respiratory pathology: a review. Eur Respir J 2008;32:1354-1370.

- 2 Tuon F, Guedes F, Fernandes E, Pagliari C, Amato $\mathrm{V}$, Seixas $\mathrm{M}$ : In situ immune responses to interstitial pneumonitis in human visceral leishmaniasis. Parasite Immunol 2009; 31:98-103.

-3 Marshall BG, Kropf P, Murray K, Clark C, Flanagan A, Davidson R, Shaw R, Müller I: Bronchopulmonary and mediastinal leishmaniasis: an unusual clinical presentation of Leishmania donovani infection. Clin Infect Dis 2000;30:764-769.

-4 Herrejón A, Cervera A, Maciá M, Ferrer R, Blanquer R: Adenoma bronquioloalveolar asociado a bronquitis obliterante y leish-

A Very Infrequent Cause of Persistent

Cough in an Asthmatic Patient maniasis pulmonar en el sida. Arch Bronconeumol 2005;41:233-235.

5 Casado JL, Cuesta C, Sánchez JA, Guerrero A: Solitary pulmonary nodule due to Leishmania in patient with AIDS. Clin Infect Dis 1998;26:532-534.

6 Matheron S, Cabie A, Parquin F: Visceral leishmaniasis and HIV infection: unusual presentation with pleuro-pulmonary involvement, and effects of secondary prophylaxis. AIDS 1992;6:238-240.

7 Nigro L, Montineri A, La Rosa R, Zuccarello $\mathrm{M}$, Lacobello C, Vinci C, Gulizia R, Fatuzzo F: Visceral leishmaniasis and HIV co-infection: a rare case of pulmonary and oral localization. Infez Med 2003;11: 93-96.
8 Viglianesi A, Di Mauro D, Petrillo G: Multidetector computed tomography aspects of tracheal mucosal leishmaniasis localization. Jpn J Radiol 2011;29:59-62.

-9 Piens MA, Arpin D, Rabodonirina R, Loire R, Brune J: Sténose trachéale d'aspect inflammatoire. Rev Pneumol Clin 1997;53:150-152.

10 Kotsifas K, Metaxas E, Koutsouvelis I, Skoutelis A, Kara P, Tatsis G: Visceral leishmaniasis with endobronchial involvement in an immunocompetent adult. Case Report Med 2011, DOI: 10.1155/2011/561985.

11 Valcárcel Y, Bastero D, Anegón M, González S, Gil A: The epidemiology of hospital admissions due to leishmaniasis in Spain (1999-2003) (in Spanish). Enferm Infecc Microbiol Clin 2008;26:278-281. 